\title{
Organizações contra-hegemônicas e a possibilidade de redescoberta da política na modernidade: uma contribuição a partir do pensamento de Hannah Arendt
}

\author{
Counter-hegemonic organizations and the possibility of rediscovering politics in modernity: \\ a contribution through Hannah Arendt's thought
}

\author{
Lara Bethânia Zilio ${ }^{1}$ \\ Rebeca de Moraes Ribeiro de Barcellos ${ }^{2}$ \\ Eloise Helena Livramento Dellagnelo ${ }^{3}$ \\ Selvino José Assmann ${ }^{4}$
}

\section{Resumo}

Este artigo apresenta um ensaio de natureza teórica cujo objetivo é situar um referencial capaz de abordar organizações que, instaladas numa forma social como sujeitos políticos coletivos, constituem-se como alternativas. Partimos do pensamento de Hannah Arendt, para quem política é a ação que busca acordos, ação em conjunto, reflexo da condição plural do homem e fim em si mesma. Com base nesta perspectiva, procurou-se demonstrar que do mesmo modo que o sistema capitalista cristaliza o esquecimento da política nos tempos atuais, o modelo hegemônico de organizar e a abordagem teórica tradicional dos estudos organizacionais (reflexos do sistema do capital) são instrumentos de despolitização e dominação social, ao legitimarem as necessidades de produção, acumulação e regulação na sociedade contemporânea. Nesse contexto, pensa-se nas organizações contra-hegemônicas como uma possibilidade de recuperação da política em suas determinações agonísticas. Nessas organizações, muito mais o grupo e as pequenas comunidades em movimento representam possibilidades de espaços políticos de fundação, resistência, civilidade e de revelação dos homens como agentes, através do exercício das categorias propostas por Arendt: identidade, pluralidade e capacidade de iniciar algo novo.

Palavras-chave: Hannah Arendt. Política. Organizações contra-hegemônicas.

Artigo submetido em 01 de junho de 2012 e aceito para publicação em 10 de outubro de 2012.

1 Bacharel em Administração pela Universidade Federal de Santa Catarina (UFSC); Mestranda do Programa de Pós-Graduação em
Sociologia Política (UFSC). Endereço: Centro de Filosofia e Ciências Humanas. Campus Universitário UFSC - Trindade, CEP 88040-
900, Florianópolis-SC, Brasil. E-mail: zilio.lara@gmail.com
2 Mestre em Administração pela ESAG - Universidade do Estado de Santa Catarina (UDESC); Doutoranda do Curso de Pós-
Graduação em Administração (CPGA) - Universidade Federal de Santa Catarina (UFSC). Endereço: Centro Sócio-Econômico, Bloco
B, Sala 224, Campus Universitário - Trindade, CEP 88040-900, Florianópolis-SC, Brasil. E-mail: rebecamribeiro@gmail.com
3 Doutora em Engenharia de Produção - EGP/Universidade Federal de Santa Catarina (UFSC); Coordenadora e Professora do Curso
de Pós-Graduação em Administração (CPGA) - Universidade Federal de Santa Catarina (UFSC). Endereço: Centro Sócio-
Econômico, Bloco B, Sala 224, Campus Universitário - Trindade, CEP 88040-900, Florianópolis-SC, Brasil. E-mail:
eloise@cse.ufsc.br
4 Doutor em Filosofia pela Pontificia Università Lateranense, Roma, Itália; Professor Titular do Departamento de Filosofia (CFH) -
Universidade Federal de Santa Catarina (UFSC). Endereço: Centro de Filosofia e Ciências Humanas, Campus Universitário -
Trindade, CEP 88040-900, Florianópolis-SC, Brasil. E-mail: selvino@cfh.ufsc.br 


\begin{abstract}
This paper presents a theoretical essay which aims to situate a framework able to address organizations that, established in a social way as collective political subjects, present themselves as alternatives. One is based upon Hannah Arendt's thought, according to whom politics is the action which seeks agreements, joint actions, a reflection of the plural condition of man, and an end in itself. Thus, taking this perspective as a foundation, one tried to demonstrate that, in the same way how the capitalist system crystallizes political forgetfulness in modern times, the hegemonic organizing model and the traditional theoretical approach of organizational studies (reflections of the capital system) are tools for depoliticization and social domination, as they legitimize the needs for production, accumulation, and regulation in contemporary society. In this context, one thinks of counter-hegemonic organizations as a possibility for recovering politics with regard to its agonistic purposes. In these organizations, the groups and small moving communities represent major possibilities of political spaces for the foundation, resistance, civility, and disclosure of men as agents, practicing the categories proposed by Arendt: identity, plurality, and ability to start something new.
\end{abstract}

Keywords: Hannah Arendt. Politics. Counter-hegemonic organizations.

\title{
Introdução
}

Nos dias de hoje, percebe-se que um sentimento de conformismo vem se instaurando pela aparente ausência de alternativas ao modo como a sociedade está organizada. Isso ocorre porque nos últimos séculos sobretudo depois que a modernidade se reduziu à modernidade capitalista - procedeu-se à eliminação da perspectiva agonística, ou seja, do caráter expressivo e heroico da ação política. Da mesma forma, houve uma liquidação sistemática das alternativas, quando elas, tanto no plano epistemológico quanto no plano prático, não se compatibilizaram com as práticas hegemônicas (SANTOS, 2003). Contra este "epistemicídio", Santos (2003) propõe a revalorização da perspectiva agonística da política, dos conhecimentos e das práticas não hegemônicas, as quais representam, afinal, a maioria das práticas de vida e de conhecimento no interior do sistema mundial.

Entende-se por organização contra-hegemônica as práticas de resistência aos discursos de gestão dominantes que buscam contestar e escapar à disciplina da ordem do sistema capitalista (SULLIVAN, SPICER e BÖHM, 2011), ou seja, uma organização como meio para a efetivação de projetos políticos (MISOCZKY, FLORES e MORAES, 2010), a qual pode ser representada por movimentos sociais como sujeitos políticos coletivos (SPICER e BÖHM, 2007; MISOCZKY, FLORES e MORAES 2010). O caráter contrahegemônico dessas organizações se destaca numa conjuntura em que o discurso gerencialista é a abordagem dominante não só nos estudos organizacionais, mas que também invade cada vez mais todas as esferas da vida humana associada (CHANLAT, 1999; PARKER, 2002; RAMOS, 1989). Segundo Dussel (2005 apud MISOCZKY, 2010), alguns traços dessa organização seriam: a formulação de uma vontade democrática participativa horizontal em todos os níveis e a centralidade da educação na produção, reprodução e desenvolvimento da vida humana feliz em uma comunidade política sem discriminações. De acordo com Misoczky (2010), essa definição de organização encaminha os estudos organizacionais para uma atividade teórica comprometida com a transformação da realidade; uma atividade crítica que toma como referência a possibilidade do desenvolvimento da vida humana em geral e, como sua condição, a possibilidade da produção e reprodução da vida dos mais afetados pelo sistema.

O objetivo deste estudo é buscar estabelecer relação entre as características das organizações contrahegemônicas e a possibilidade de retomada da política em suas determinações democráticas originárias. Por outras palavras, trata-se da redescoberta da política com muita política, onde o protagonista, mais do que o próprio governo e as instituições formais da política, é muito mais o grupo, o conjunto dos cidadãos em movimento (NOGUEIRA, 2001). 
De tal modo, este artigo busca recuperar o sentido da política no seu aspecto agonístico, plural e participativo. Por esse motivo, os autores recorreram especialmente à politóloga alemã Hannah Arendt, que não pretendeu insular a política do conflito, do antagonismo e mesmo da guerra. Segundo Arendt, tal atitude teórica teria sido considerada mais uma dentre as muitas tentativas filosóficas de se construir idealmente uma política pacificada e infensa à possibilidade do advento da novidade no mundo (DUARTE, 1994). Pode-se dizer que, de acordo com Arendt (1998), pensar uma política alheia ao conflito - e, no limite, totalmente alheia à violência - equivale a negar que a política seja constitutiva da ação e, portanto, capaz de gerar o novo:

O que faz do homem um ser político é sua faculdade para a ação; ela o capacita a reunir-se com seus pares, a agir em concerto e a almejar objetivos e empreendimentos que jamais passariam por sua mente, para não falar nos desejos de seu coração, se a ele não tivesse sido concedido esse dom - o de aventurar-se em algo novo. (ARENDT, 1998, p. 113)

\section{A Política na Visão de Hannah Arendt}

Arendt (2010) procurou desenvolver uma fenomenologia da ação política e do espaço público ao buscar trazer à tona determinações democráticas essenciais, através da análise fragmentária das experiências políticas originárias da pólis ${ }^{5}$ democrática ateniense e da res publica romana, cujo núcleo se encontraria preservado, mesmo precariamente, na linguagem política do Ocidente. Retomar esse núcleo originário da experiência política ocidental não significa pretender repetir no presente um conjunto de acontecimentos pretéritos, mas visar, no passado, àquilo que nele é ainda novo, não pensado, verdadeiro manancial de possibilidades políticas encobertas e não abordadas pela filosofia política.

Nem saudosismo nostálgico, satisfeito em lamentar aquilo que foi a política antiga; nem a arrogância teórica de pretender determinar, pela construção racional de modelos normativo jurídico políticos, aquilo que a (boa) política "deve" ser; antes, e por outro lado, Arendt levou a cabo uma discussão daquilo que "é" a política, à luz da descoberta, no passado, daquilo que ela ainda pode ser hoje e no futuro. (DUARTE, 1994, p. 8-9)

Sobre a origem da política e do poder, Arendt (2010, p. 249) sustenta que ambos surgem do espaço da aparência que vem a existir sempre que os homens se reúnem na modalidade do discurso e da ação. Trata-se de um espaço que precede a toda e qualquer instituição formal da esfera pública e às várias formas de governo, cuja existência mesma depende diretamente de que os homens permaneçam juntos e dispostos a agir e falar entre si, desaparecendo quando eles se vejam isolados uns dos outros. Nesse sentido, trata-se também de um espaço que existe potencialmente. Isto é, a política existe como possibilidade, nunca se reduzindo à sua institucionalidade ou às suas instituições.

Esse modo de conceber e praticar a política tem em seu centro a educação dos cidadãos: um esforço permanente para fazer com que todos aprendam a valorizar o diálogo e o alcance do consenso como meio de resolver conflitos, organizar e viver a vida, o que ocorre em proporção tanto maior quanto for a corresponsabilidade de cada um no consenso alcançado. É uma retomada da ideia grega de política, que, como escreveu Arendt (2010), explora ao máximo a essência eminentemente política, comunitária, dialógica e comunicativa do homem. Uma ideia que não tem como se afirmar sem se unir à perspectiva de Paideia, ou

${ }^{5}$ Segundo Arendt (2010, p. 248), a pólis é uma organização que resulta do agir e falar em conjunto, e o seu verdadeiro espaço situa-se entre as pessoas que vivem juntas com tal propósito. Isto é, a pólis não deve ser entendida como o espaço físico da cidade-Estado. 
seja, daquele processo contínuo dedicado à formação integral do homem, concentrada no bem comum, no aproveitamento civilizado do conflito e da diferença, na valorização do diálogo, do consenso e da comunicação, na defesa crítica e na participação, numa operação que se volta para a aposta na inesgotável capacidade criativa dos homens.

Logo, de acordo com Arendt (2010), a política não poderia dar-se prioritariamente no campo do trabalho, pois o trabalho não é uma atividade com a qual o homem se identifique e na qual encontre auto aperfeiçoamento. Para Arendt (2010), o ser humano não é produto do próprio trabalho, pois este apenas proporciona a sobrevivência biológica do ser humano. Por isso, o trabalho nunca se transforma dialeticamente em algo outro que ele mesmo, nem engendra transformações qualitativas naqueles que o empreendem. Arendt, ao contrário de Marx e Engels, e - podemos dizer, mutatis mutandis, à diferença de toda tradição liberal - não confia no poder de negação e de transformação dialética, afirmando que o reino da necessidade possa engendrar o reino da liberdade, e que a emancipação do homem em relação ao trabalho possa ser o objetivo de uma revolução política. Mais imperativo do que a emancipação da classe operária e sua luta política pela igualdade universal foi o processo de emancipação da própria atividade do trabalho, que precedeu em vários séculos a emancipação política dos trabalhadores e teve como resultado o crescente processo de homogeneização do homem, nivelando-se assim todas as atividades humanas ao denominador comum de assegurar as coisas necessárias à vida e produzi-las em abundância (ARENDT, 2010, p. 157).

Resta então dizer que o que se pretende destacar ao analisar a concepção de política no pensamento de Hannah Arendt é que a mesma implica não só a possibilidade, latente em todos os seres humanos, de criar algo novo, fazendo surgir o inesperado, o imprevisível, mas ainda - e não em segundo plano - a pluralidade política, a qual nunca se realiza no isolamento, sendo sempre uma ação em conjunto, plural, entre iguais. Por conseguinte, a política, apesar de ser iniciada pela espontaneidade humana, surge como relação; ela existe entre homens. Em outras palavras, não é da essência do homem, considerado isoladamente, mas tem a ver com o fato de os homens viverem num mundo plural, em comunidades (ARENDT, 2010).

Como aposta nas vantagens da comunidade - do latim communitas, referente ao que é comum, a política é acima de tudo uma aposta na participação política; isto é, na disposição para interferir no rumo dos eventos, um empenho em ser sujeito ativo dos processos coletivos. De acordo com Nogueira (2001), a política em seus estágios mais avançados é a aposta na participação democrática, dedicada a refundar o poder, a transformá-lo em algo mais acessível, menos ameaçador e mais compartilhado. Sua maior promessa é fundamentar uma nova sociabilidade, solidária e democrática, mas sempre agonística, na qual todos possam coexistir como sujeitos, seja no espaço das organizações, nos grupos e nas associações de modo geral (NOGUEIRA, 2001, p. 29).

Para Arendt (1990), a ação política só poderá ser entendida como liberdade se a mesma não sofrer qualquer forma de funcionalização ou de instrumentalização, como acontece, sobretudo, no campo do trabalho, cujo valor não estaria, ao contrário da ação política, no desempenho em si mesmo, mas sim em algum resultado, um fim a ser alcançado quando termina o processo produtivo. Tal como as artes de realização, caso da música, da dança e do teatro, a política não é meio para outro fim. É um fim em si mesma, e como tal deve ser valorada pelo seu "virtuosismo" - entendido este a partir do conceito amoral de virtù de Maquiavel -, como performance, além de necessitar de uma "audiência" e de um espaço para que o "espetáculo" possa se realizar (DUARTE, 2001).

Nesse sentido, o pensamento de Hannah Arendt mostra-se fecundo para a compreensão das vias de acesso às práticas que repõem, na sociedade do capital, a política na sua significação original. Mesmo que haja 
controvérsias, ${ }^{6}$ através da concepção de ação humana, Arendt (2010) estrutura três categorias que, se restauradas, podem vir a possibilitar nos dias atuais a retomada do sentido originário e democrático da política, a saber: identidade, pluralidade e capacidade de iniciar algo novo.

De acordo com Arendt (2010), pensar a política na chave da identidade é a única forma de superar a sua redução a meio, a instrumento e retomar sua dimensão agonística e de conflitos. No critério da excelência, o que está em jogo não é o biológico, não é a redução da atividade humana a função; tampouco, é o interesse econômico, mas o surgimento de um lugar para a revelação dos sujeitos como autores da própria existência. No pensamento de Arendt (2010), assim como para Santos (2003), a superação da atual crise da política não pode ser operada pela conversão dos corações dos políticos ou dos cidadãos, e sim pela elaboração de espaços públicos capazes de acolher a demanda identitária de todos os seres humanos.

Outra categoria a ser recuperada na modernidade é a existência da pluralidade como condição humana. Para Arendt (2010), a pluralidade humana é uma realidade ontológica, inerente ao fato de haver homens, e não o homem, que habitam a Terra. Vale dizer também que, assim como a pluralidade é inerente ao fato de cada homem viver entre homens, a liberdade também o é, pois só se é livre quando se divide o mundo com outras pessoas. Portanto, não existe liberdade absoluta, total. Assim, a ação política é a forma mais apropriada de lidar com os conflitos entre os homens e não uma forma de desconhecê-los (ARENDT, 2010).

A terceira categoria a ser recuperada nos dias de hoje de acordo com Arendt (2010) é a capacidade humana de iniciar algo novo e de romper com o status quo. Para Arendt (2010), enquanto existirem seres humanos, a capacidade de iniciar irá perdurar viva. Mesmo em situação de vigência de manipulabilidade geral - que é a grande aposta da atual estratégia que privilegia a atuação dominadora sobre as condições da ação -, o homem retém a capacidade de iniciar algo novo. Iniciar é a característica fundamental da ação. É nisso que ela se diferencia das demais atividades humanas e é o motivo pelo qual a redução do ser humano a um passivo consumidor de apetrechos ou trabalhador não é admissível no pensamento dessa autora.

\section{Crítica ao Sistema de Capital e ao Esquecimento Político na Modernidade}

O objetivo final do sistema do capital era transformar a produção numa atividade científica e prover a sociedade de capacidades de processamento de alta taxa de produtividade, simultaneamente, liberando os homens do trabalho. No entanto, no decurso dos três últimos séculos, o aumento indefinido da produção de mercadorias e o progresso tecnológico indiscriminado, ao invés de conduzirem à naturalização do potencial do homem, têm, de fato, potencializado as limitações e a influência desfiguradora desse sistema na vida humana como um todo (RAMOS, 1989). Isso ocorre tanto pela crescente mercantilização da satisfação das necessidades, quanto pela cultura de consumo que lhe está associada e o legitima (BAUDRILLARD, 1995; SANTOS, 2003).

Neste contexto, o capitalismo é hoje menos um modo de produção que um modo de vida (SANTOS, 2003) no qual a racionalidade instrumental substituiu a racionalidade substantiva ${ }^{7}$, tornando-se a lógica dominante de ordenação política e social da vida humana ao fomentar o controle da natureza através do desenvolvimento de forças produtivas (RAMOS, 1989).

\footnotetext{
${ }^{6}$ Muitos intérpretes das obras de Hannah Arendt acreditam que a autora tenha se limitado a uma concepção negativa das possibilidades políticas modernas ao considerarem suas críticas às difíceis condições que a modernidade e o mundo contemporâneo reservam ao exercício da política como exclusivas.

${ }^{7}$ Como herança dos pensadores clássicos, o debate racional (substantivo) é a essência da forma política de vida e requisito essencial para o suporte de regulação da vida humana associada (RAMOS, 1989).
} 
O sistema do capital se mantém alicerçado no surgimento da sociedade na modernidade e ao universalismo jurídico adotado, ou seja, a igualdade artificial dos homens como cidadãos (NOGUEIRA, 2001). A ideia de direitos igualitários não se dissocia completamente do sujeito individual e concebe para si, como cenário ótimo, o espaço e a lógica do mercado: autonomias privadas, indivíduos independentes, contratos, garantias e relações de troca. Nessa conjuntura, as proclamações de direito tornam-se vazias de maiores considerações a respeito do contexto social abrangente e dos demais membros da comunidade (DUMONT, 2000). Da mesma forma, o ideal da funcionalização e automatização da vida exibe como insignificante o contato entre os homens como seres humanos, tornando-os meras funções sociais, coisas (NOGUEIRA, 2001).

Para Arendt (1990), em boa medida, o progresso e a barbárie coexistem e se mesclam na sociedade capitalista, enquanto um circuito de deterioração e desagregação social continua permanentemente ativado. Extinguem-se, assim, o espaço para o dissenso e para a dimensão plural dos seres humanos pelas necessidades de expansão da força, da governabilidade e da eficácia. Daí porque Arendt (1990) entende o Estado liberal como assentado na desvalorização do político como uma arena pública. O liberalismo vê como principal meta da sociedade, garantir o espaço privado da liberdade, assegurando que não haja interferências na individualidade de cada um. Ao contrário da concepção moderna, para os antigos, a liberdade não é uma liberdade interior e preexistente em cada indivíduo, mas algo que só se constitui pela ação conjunta no espaço público ${ }^{8}$. Nesse contexto, Gramsci (2002) dialoga com Arendt (1990) ao enfatizar a ideia de que se não soubermos abrir mão de parte de nossos desejos e interesses, se não soubermos ceder em nome de certos compromissos e projetos coletivos, não teremos como viver em sociedade (grupo, organização), nem teremos como ser efetivamente autônomos.

Sobre o obscurecimento das determinações políticas democráticas no sistema de capital, Nogueira (2001, p. 13) discursa:

Há tanta técnica, tanta ênfase na produtividade e na decisão rápida, pragmática, racional, que o ritmo lento e a natureza sanguínea da política se mostram como ineficácia, desperdício, insensatez. [...] tudo pressiona a política a se converter numa outra coisa, mais fria, mais especializada e mais distante dos cidadãos comuns.

Na mesma linha, Arendt (2010) defende que onde a política não foi reduzida ao plano da violência ou ao plano da administração burocrática dos interesses econômicos, ela esvaece-se pela apatia conformista característica das sociedades contemporâneas, onde a capacidade humana para agir espontaneamente foi substituída pelo mero comportamento, em sua monótona previsibilidade repetitiva e normatizada. Dessa forma, o desenvolvimento capitalista impõe limites à livre e genuína comunicação entre os seres humanos e a ação política, ao enfraquecer as referências e linguagens comuns (RAMOS, 1989).

De acordo com Nogueira (2001), o enfraquecimento da política é o embaçamento das condições para que se supere o mal-estar coletivo - ou seja, a dificuldade de compor o que é comum pela primazia do privado sobre o público - e se encontre um novo rumo. Nesse sentido, a ideia de esquecimento da política sugere que a crise da política chega ao âmago da vida social, ao dificultar o acúmulo de energia para que se explorem os elementos virtuosos que emergem daquilo que se desagrega e se desorganiza.

Para Nogueira (2001, p. 21), "o horror à política expressa a dificuldade que as comunidades estão tendo não só de se adaptar a um quadro de crise e mudança acelerada, mas, sobretudo, a governá-la, dirigi-la e superála". Assim, a perda de confiança na política estimula a marginalização de boa parte da população, ao obstruir a principal passagem para uma transformação social; isto é, a via das mudanças progressivas decorrentes de

${ }^{8}$ Para Arendt (1990), o conceito de espaço público é central e representa o contraponto ao espaço privado, o qual é visto como inspiração de interesses materiais, da covardia e do temor da ação entre os homens. 
lutas e pressões diuturnas, fundada na mobilização de massas organizadas e habilitadas para negociar, impor e garantir conquistas.

A tendência de domínio e de controle total da sociedade, não diretamente sobre as vontades, mas sobre as condições da existência da vida humana, transforma-se na grande tendência das sociedades capitalistas, ao inviabilizar os contatos político-organizacionais e espontâneos entre as pessoas. Assim, o sistema de capital parece libertar "os indivíduos das tradições e práticas coletivas do passado, que constrangiam sua autonomia e os oprimiam, mas não os impulsiona em direção a outras e melhores formas de sociabilidade" (NOGUEIRA, 2001, p. 96).

\section{Crítica ao Modelo Hegemônico de Organizar $^{9}$}

A imposição gradual da lógica capitalista associada à difusão massiva dos discursos e das práticas de gestão empresarial em setores mantidos até então à margem dessas práticas, caracteriza o fenômeno histórico designado por Solé (2003) como "empresarização do mundo". Nele, a base da sociedade vê aumentar sua diferenciação, ao mesmo tempo em que é condicionada por uma agressiva padronização dos gostos, comportamentos e pela apatia ao comum e ao coletivo.

A crescente disciplina e o progressivo ritmo das organizações fazem com que o modelo de gestão hegemônico centrado no mercado e reflexo do mesmo, espalhe-se por todas as esferas da vida humana social, ao moldar os modos de ser, agir, sentir, pensar e imaginar (CHANLAT, 1999; PARKER, 2002). Dessa maneira, podemos afirmar que aquilo que hoje chamamos de política, cada vez mais, vem se transformando em mera capacidade de gestão do bem público, e muito pouco ainda é, ou consegue ser, um exercício público e plural de liberdade. Com bases fortemente alicerçadas nas correntes de pensamento ligadas ao racionalismo, positivismo, utilitarismo e funcionalismo, as abordagens tradicionais dos estudos das organizações apresentam perspectivas unilaterais, ao incorporar discursos e práticas que obscurecem as tensões inerentes às relações dialéticas do campo (BÖHM, 2006; MISOCZKY, FLORES e MORAES, 2010; PAES DE PAULA, 2002; PAES DE PAULA e RODRIGUES, 2006;). Ainda, sob o argumento de neutralidade científica, valores como máxima produtividade, racionalização e eficiência são cultivados pelo ethos ideológico da ciência, que faz uso de modelos que naturalizam a razão técnica condicionada historicamente, projetando ao futuro a lógica capitalista (TRAGTENBERG, 2006).

De acordo com a visão crítica dos estudos organizacionais, a abordagem tradicional é inadequada para a compreensão da vida social, conduzindo à nulidade política, e está relacionada com a tecnocracia e sua dominação (TENÓRIO, 1998). O resultado dessa dominação é a legitimação social e moral da empresa como forma de organizar hegemônica, ao representar uma organização racional baseada em funções técnicas ditas objetivas e necessárias para o funcionamento efetivo e eficiente da ordem social no sistema do capital (CLEGG e HARDY, 1996).

Böhm (2006) chama a atenção para a necessidade de posicionamento da organização no contexto da sociedade, no sentido de se estabelecer claramente a respeito do que está se tratando e quais os pressupostos aos quais se está referindo. De acordo com o autor, a noção dominante de organização está restrita a entidades formais e instituições nas quais a organização social parece sempre já formada, predeterminada e

${ }^{9}$ O termo hegemonia, consagrado por Gramsci, refere-se, aqui, a um alinhamento do discurso político que produz um significado social específico. Hegemonia não deve ser confundida com uma totalidade que fixa o significado social para sempre. Em vez disso, as noções de hegemonia e contra-hegemonia indicam que uma multiplicidade de resistências desafia continuamente os significados da ordem social estabelecida (GRAMSCI, 2002). Indicam também a existência de infinitas possibilidades de como a sociedade pode vir a ser organizada, e que as sementes de mundos organizacionais diversos estão entre nós. 
dada. Vista dessa maneira, referir-se à organização significa remeter-se à administração e à manutenção de um mundo ordenado e técnico, caracterizado pela divisão do trabalho, pelo profissionalismo, pela burocracia e por corpos racionais que podem ser alocados, medidos e representados. Dessa perspectiva, segundo Böhm (2006), organizar refere-se ao posicionamento de coisas e sujeitos num local simples, formal, hierárquico e claramente definido.

Nesse movimento de posicionamento, Böhm (2006) afirma que o modelo hegemônico de organização é caracterizado por uma visão de organização que não pode ser desconectada do gerencialismo e do capital global, de forma que o conceito de organização é costumeiramente restrito à descrição do que está se passando dentro e em torno de instituições gerencialistas, empresas e locais de trabalho, posicionando claramente a organização como uma entidade formal dentro de estruturas estabelecidas da modernidade e do capitalismo. Essa maneira racional e formal de situar a organização tem sido a ideologia predominante da teoria organizacional, uma visão que Böhm compartilha com outros autores, como Clegg (1998) e Parker (2002), por exemplo. Assim, a denúncia - e, portanto, a desnaturalização da articulação hegemônica da organização - é uma das ações políticas mais imperativas nos dias de hoje, ao permitir a imaginação de diferentes mundos e sociedades (MISOCZKY, FLORES e BÖHM, 2008).

Böhm (2006) afirma ainda que as forças que buscam um posicionamento absoluto da realidade sempre estarão acompanhadas por forças de subversão, resistência ou desposicionamento, as quais precisam ir além das noções restritas de organização, questionando o posicionamento dominante. Compartilhando dessa visão, Schreven, Sverre e Svensson (2008) lembram que existem muitas formas de organizar a vida social diferentes das baseadas e ditadas pelo tipo de mercado livre que reina em grande parte do mundo, perspectiva presente também nos estudos de autores críticos brasileiros como Guerreiro Ramos e Maurício Tragtenberg.

A visão de Ramos (1989) é esclarecedora no sentido de mostrar que a sociedade é constituída por uma variedade de enclaves, entre os quais se situa o mercado e nos quais o homem se empenha em atividades diversas. O paradigma paraeconômico proposto por Ramos (1989) vem chamar a atenção para o fato de que existem outras formas de organização humana que não a forma burocrática tipicamente abordada pelos estudos organizacionais. São exemplos dessas possibilidades de organização:

- a isonomia - um tipo de organização social em que todos os membros são iguais e cujo objetivo é sua atualização mediante a realização de atividades compensadoras em si mesmas; e a

- fenonomia - sistema social de caráter mais ou menos estável que permite aos seus membros o máximo de opção pessoal e um mínimo de subordinação a prescrições formais (RAMOS, 1989).

Misoczky (2010) questiona também a crença em um único modo de organizar, vinculada de forma restrita ao modo burocrático, o qual a autora toma como sinônimo de prática gerencial. Conforme afirma a autora (2010, p. 33), "organizar é produzir socialmente modos de cooperação, sempre instáveis e em movimento".

A partir de uma noção mais abrangente de organização, Clegg (1998) ressalta a necessidade de estudos voltados para formas e práticas organizacionais ainda não interpretadas. Misoczky e Vecchio (2006) também entendem que é necessário considerar outras formas de organizar. Para eles:

precisamos mergulhar em algumas organizações que experimentam formas não-gerenciais de convivência em nosso contexto de formação social periférica para, a partir da vivência destas práticas, alimentarmos nossas reflexões teóricas e podermos, assim, usar nosso fazer acadêmico como uma contribuição para novos agenciamentos e para a disseminação da esperança. (MISOCZKY e VECCHIO, 2006, p. 10) 
Misoczky (2010) corrobora esse ponto de vista argumentando que uma das tarefas políticas mais importantes dos estudos críticos na área de organizações é explorar os processos de organização da resistência e das lutas sociais que tendem a ser ignoradas pelo discurso organizacional contemporâneo. Nesse sentido, o estudo desenvolvido por Spicer e Böhm (2007) mostra que existem organizações com práticas que desafiam o modelo vigente, não se submetendo à sua lógica e desafiando a estrutura do campo, as quais os autores chamam de práticas de resistência.

\section{A Possibilidade de Redescoberta do Político em Organizações Contra-Hegemônicas}

Quando processos de organização de resistência e de lutas sociais estabelecem uma articulação coerente entre projetos políticos e a organização como meio para efetivar tais projetos e possibilitar a ruptura com as formas dominantes, temos organizações consideradas contra-hegemônicas (BÖHM, 2006; SULLIVAN, SPICER e BÖHM, 2011).

A resistência à hegemonia da gestão pode ser encontrada em espaços diversos: pelo trabalhador no seu local de trabalho, pelas organizações sindicais, pelos movimentos sociais e pelas organizações sociais. O interrelacionamento entre essas diferentes formas é o que permite estabelecer lógicas de equivalência entre elas, as quais, mesmo atuando cada uma à sua maneira, acabam por gerar movimentos globais de resistência ao gerencialismo e à globalização como esta é entendida pela visão hegemônica (SPICER e BÖHM, 2007).

Parker (2002) acredita que os movimentos sociais são importantes espaços de resistência ao capitalismo, à forma organizacional dominante e à globalização por ela pretendida. No mesmo sentido, Escobar (2004) afirma que esses movimentos sugerem novidades, se comparados à forma tradicional de organizar, pois organizam seguindo outra lógica e têm diferentes bases de mobilização social. Na visão desse autor, os movimentos sociais articulam diferentes lógicas de política e mobilização porque produzem autoorganização e redes sociais não hierárquicas, além de habilitarem políticas locais. O fato de esses movimentos questionarem a epistemologia do mercado em nome de alternativas os configura como movimentos antiglobalização, pelo que suas propriedades permitem vislumbrar outras possibilidades (ESCOBAR, 2004).

Essas organizações, que de uma forma ou de outra questionam o modelo dominante de organização, vêm recebendo nomes diversos, conforme o enfoque adotado. Economia solidária, organizações alternativas, organizações substantivas, organizações autogestionárias, organizações horizontalizadas, organizações coletivas e organizações da sociedade civil são tratamentos encontrados em discussões envolvendo o tema.

De acordo com Knoke (1990), por exemplo, existe mesmo uma variedade de organizações coletivas que buscam soluções não mercadológicas para problemas individuais ou coletivos. O que elas têm em comum, na visão do autor, é a base de participação voluntária, podendo eventualmente serem contratadas pessoas sob a autoridade de líderes organizacionais e o estabelecimento de procedimentos democráticos formais no intuito de envolver os membros nas decisões políticas.

Andion (2005) aponta como características dessas organizações, próprias da economia social, o papel social proveniente de um projeto definido, as iniciativas caracterizadas como espaços enraizados na esfera pública, a participação dos atores na gestão coletiva e a gestão financeira baseada na hibridização de diferentes fontes de financiamento.

Nessas organizações, o esquema tradicional de gestão burocrática é contraposto ao que Tenório (1998) chama de gestão social. Para esse autor, a gestão social se contrapõe à gestão burocrática, na medida em que busca um gerenciamento mais participativo, dialógico com o processo decisório, gerenciamento esse 
exercido por diferentes sujeitos sociais por meio da racionalidade comunicativa, em busca de soluções consensuais.

Esses princípios de gestão estão presentes nas organizações da economia solidária (ANDION, 2005; BALBINOT e PEREIRA, 2007; BEHR e PAES DE PAULA, 2008; COSTA e CARRION, 2008), nas organizações autogestionárias (FARIA, LEAL, ATTIE et al., 2008; FARIA, PONTES, LEAL et al., 2008, MICOSZKI, SILVA e FLORES, 2008), na mídia contra-hegemônica (FRENZEL, BÖHM, SULLIVAN et al. 2011; SULLIVAN, SPICER e BÖHM, 2011; YOUNG e BÖHM, 2007) e apresentam características diversas das organizações burocráticas tradicionalmente analisadas. Para Costa e Carrion (2008, p. 11), abordar essas organizações "é inovador porque provoca uma avaliação permanente do que está posto como inquestionável, desde as relações de trabalho e de gestão até a construção de projetos políticos macrossociais".

Partindo das três categorias que, na visão de Arendt (1973), podem vir a possibilitar nos dias atuais a retomada do sentido originário e democrático da política, podemos refletir sobre algumas relações entre as práticas de organizações contra-hegemônicas e as noções de identidade, pluralidade e capacidade de iniciar algo novo.

A adesão voluntária destacada por Knoke (1990) é um aspecto comum às organizações contra-hegemônicas, facilitando o exercício da identidade do sujeito, na medida em que ele tem livre acesso à organização, assim como também é livre para desligar-se dela no momento em que considerar adequado. As relações igualitárias proporcionadas pelas estruturas horizontalizadas e pelos processos de tomada de decisão participativos, como nos casos da autogestão (FARIA, LEAL, ATTIE et al., 2008; FARIA, PONTES, LEAL et al., 2008; MICOSZKI, SILVA e FLORES, 2008) e da economia solidária (ANDION, 2005; BALBINOT e PEREIRA, 2007; BEHR e PAES DE PAULA, 2008; COSTA e CARRION, 2008) podem proporcionar um ambiente favorável à manifestação do indivíduo, a partir do que se podem reunir e acolher demandas identitárias diversas.

Young e Böhm (2007) identificam no estudo da organização de mídia contra-hegemônica IfiWatch um processo de formação de uma identidade coletiva. Esta iria além do exercício das identidades individuais, ao instituir uma lógica de equivalência, no sentido usado por Laclau e Mouffe (2001), estabelecendo entre elas um "nós x eles" dentro de um campo antagônico de relações políticas, como é o da contra-hegemonia no enfrentamento à hegemonia. A identidade da Indymedia - outra organização de mídia contra-hegemônica - é construída e consolidada por meio do exercício ativo e democrático de seus membros, e reafirma-se ao ser desafiada por posições hegemônicas, conforme tentam mostrar Sullivan, Spicer e Böhm (2011).

O reconhecimento da pluralidade, e o respeito a ela, é uma possibilidade dentro das organizações contrahegemônicas, primeiro de tudo, se consideramos a propriedade coletiva e a tomada de decisão por todos os membros. Nesse contexto, não há diferenciação entre dirigentes e dirigidos, enquanto o poder é repartido entre diferentes sujeitos, com distintas posições articuladas em um espaço igualitário. No caso da autogestão, por exemplo, Misoczky, Silva e Flores (2008) mostram experiências que adotam práticas organizacionais diferentes das tradicionais, tendo como ponto central a descentralização das tomadas de decisão, a polivalência de funções e o desaparecimento de hierarquias salariais. Nesse contexto, há uma ruptura com a propriedade privada em direção a uma forma coletiva de propriedade dos meios de produção. Para Faria, Leal, Attie et al. (2008), além da propriedade coletiva, é característico de um empreendimento autogestionário o controle do processo de produção por todos os produtores, sendo negada a diferenciação entre dirigentes e executores, num contexto onde o axioma fundamental é o da igualdade entre as pessoas.

Frenzel, Böhm, Sullivan et al. (2011) discutem a existência de pluralidade de identidades, formas organizacionais e formas de concepção e prática de accountability em diferentes pontos de articulação de duas organizações de mídia contra-hegemônicas, tomando como pontos de referência a localização no hemisfério Norte e no hemisfério Sul. Os autores percebem que as diferenças existem e são reconhecidas 
pelos membros, não sem a existência de conflitos, os quais, no entanto, não inviabilizam a atuação colaborativa.

A própria existência de organizações contra-hegemônicas, sua sobrevivência e reprodução em espaços sociais diversos viabiliza a pluralidade, ao exercitar uma forma de organizar diferente da forma dominante, questionando e contrariando seus pressupostos fundamentais.

A capacidade de criar algo novo e de romper com o status quo parece ser uma característica fundamental das organizações contra-hegemônicas. Aspectos como tomada de decisão coletiva e mecanismos de controle definidos pelos membros (BALBINOT e PEREIRA, 2007; MISOCZKY, SILVA e FLORES, 2008) são frontalmente distintos dos princípios de gestão burocrática dominantes. Misoczky (2010) constata ainda que algumas categorias e valores têm sido cada vez mais levados em conta na análise das organizações tidas como possibilidades contra-hegemônicas. Além da horizontalidade, da participação diretas nas decisões e da construção coletiva da organização e de suas práticas, também passam a ser considerados os valores orientados para a vida e a tolerância, bem como a solidariedade na relação com o outro. Isso tem levado a mudanças nas categorias de análise mais corriqueiras nos estudos organizacionais, como hierarquia, delegação e representação, individualismo e elitismo, valores orientados para o mercado, discriminação da diferença, rotina e reprodução na práxis burocratizada (MISOCZKY, 2010).

\section{Considerações Finais}

Diante do que foi colocado até aqui, podemos formular algumas considerações gerais que podem servir como conclusões provisórias. De acordo com Duarte (2001), nos modernos eventos revolucionários, de desobediência civil e resistência, Arendt (1973) vislumbra a possibilidade da política ser revitalizada em suas originárias determinações democráticas greco-romanas por meio de sua reapropriação pelos cidadãos. Essa revitalização se daria a partir da invenção de novas formas de exercício da política e de novas formas de pensamento, capazes de recapturar e retraduzir num instante a origem democrática da política.

São esses movimentos de dissidência e resistência que mantêm o vínculo primordial com o princípio da livre associação voluntária para a ação coletiva. Tanto no passado quanto na sociedade contemporânea, o que está em jogo é a "alegria de agir, a certeza de poder mudar as coisas pelos seus próprios esforços" (ARENDT, 1973, p. 174). Assim, focos de resistência, de desobediência civil e lutas sociais articuladas por organizações contra-hegemônicas são formas de recuperação da capacidade humana de agir coletivamente e de resistir contra a arbitrariedade e a opressão, enfrentando uma mentalidade bastante presente que nos diz que não é possível nenhuma novidade, senão adaptarmo-nos ao mundo da forma como ele funciona. Tal enfrentamento pode ser tentado através de ações microfísicas ou de microrrevoluções, na perspectiva de refundarmos as bases do poder constituído, recorrendo ao potencial renovador do poder constituinte, podendo tais ações e microrrevoluções serem referenciadas, portanto, como formas contra-hegemônicas de se organizar.

Segundo Nogueira (2001), tanto as lutas sociais como movimentos contra-hegemônicos vindos da sociedade civil exigem a construção de uma malha de grandes e pequenos poderes democráticos, com os quais seja possível processar reivindicações que não representem dilacerações comunitárias, mas que, ao contrário, sejam caminhos para a construção de autonomia, de novas formas de subjetividade, de uma comunidade democrática e de um viver melhor. Em boa medida, tudo ficou na dependência de que surjam e se multipliquem espaços societais onde possam nascer e se reforçar novas formas de solidariedade, de cooperação e de participação democrática (NOGUEIRA, 2001).

A política não existe e nem pode ser pensada fora da sociedade que a determina e, em última instância, a explica. Com base nesse raciocínio, é possível pensar numa recomposição, ou seja, um meio de repor a sintonia entre a vida e a política. Afinal, podemos entender a partir daí que qualquer recomposição precisa 
partir de uma divisão de responsabilidades: a sintonia desejada depende tanto de uma iniciativa firme da própria política, quanto da instalação de uma nova dinâmica na comunidade. A política é o melhor terreno para que se possa empreender qualquer movimento de recomposição, inclusive, de si própria (NOGUEIRA, 2001). Sair em defesa da política, portanto, é uma operação destinada a defender a hipótese mesma da vida comunitária. Corresponde à necessidade vital de manter abertas as comportas de oxigênio, para que possamos continuar a respirar.

Este artigo procurou apresentar um ensaio de natureza teórica que teve o objetivo de situar um referencial teórico capaz de abordar organizações que se constituem como alternativas numa forma social instalada como sujeitos políticos coletivos. Dessa forma, a partir do referencial teórico da filosofia política especialmente do pensamento de Hannah Arendt, segundo o qual política é a ação que busca acordos, ação em conjunto, sendo reflexo da condição plural do homem e fim em si mesma -, procurou-se construir uma proposta que buscasse adequar esse referencial às organizações alternativas ao modelo hegemônico.

Através dessa análise, demonstrou-se que, do mesmo modo que o sistema capitalista cristaliza o esquecimento da política nos tempos atuais, o modelo hegemônico de organizar e a abordagem teórica tradicional dos estudos organizacionais - reflexos do sistema do capital - são instrumentos de despolitização e dominação social, ao legitimarem as necessidades de produção, acumulação e regulação em nossa sociedade. Nesse contexto, pensa-se nas organizações contra-hegemônicas como uma recuperação da política em suas determinações agonísticas, onde muito mais o grupo, as pequenas comunidades em movimento e, inclusive, a massa representam possibilidades de espaços políticos de fundação, resistência, civilidade e revelação dos homens como agentes.

Através da atualidade do pensamento de Arendt, o qual retoma a ideia grega de pólis, foi possível refletir sobre as possibilidades de mobilização política e práticas democráticas na atualidade. No entendimento de Arendt, a política - como criação do novo, do inesperado, como ação plural, resultado do amor ao mundo e não como violência -, não é apenas uma alternativa, mas algo realizável. Ela é inerente à condição humana, é uma necessidade, é essencial para a constituição do indivíduo e da comunidade na qual nos movemos. Política assim é aquela que se torna uma experiência pública de liberdade humana, e não aquela que simplesmente se reduz à gestão do dinheiro público. Desse modo, o mundo comum, as instituições, tudo aquilo que pretende realizar a mediação entre homens, erigindo mais pluralidade e menos deserto, mais experiência de liberdade e de beleza do que experimentação de receitas orçamentárias, mais compartilhamento do que isolamento, só pode ser construído se a política for sinônimo de liberdade e a organização for entendida como sujeito político coletivo.

Tendo como pressuposto que nenhuma transformação social ocorre de forma externa a uma forma social já instalada, entende-se que a relevância de se compreender a perspectiva política no interior dessas organizações contra-hegemônicas decorre do fato de que tais organizações têm o potencial de constituírem contradições que, mesmo dentro do sistema de capital, podem apontar não apenas vias para sua superação, mas também para a revitalização de espaços políticos onde existam possibilidades de restabelecimento dos laços entre a ação política, a liberdade e a felicidade coletiva.

O que se espera com esta proposta é contribuir para a reflexão sobre como reposicionar a organização no âmbito social macropolítico em detrimento da ordem disciplinar do sistema do capital e do modelo organizacional hegemônico. Mais especificamente, esta discussão se propõe a ampliar as fronteiras da produção teórica sobre as organizações como meio e aprendizagem para uma práxis criativa, ao conceber a organização como meio para a emancipação, sempre no espaço da unidade do consenso produzido no coletivo. Em suma, uma organização que venha a transformar a potência do povo em poder e que seu êxito não seja o do meio-fim formal, mas o do pleno desenvolvimento da vida de todos. 


\section{Referências}

ANDION, C. A gestão no campo da economia solidária: particularidades e desafios. Revista de Administração Contemporânea, v. 9, n. 1, 2005.

ARENDT, H. Crises da República. São Paulo: Perspectiva, 1973.

Origens do totalitarismo. Tradução de Roberto Raposo. São Paulo: Companhia das Letras, 1990.

O que é política? Fragmentos das obras póstumas. In: LUDZ, Úrsula (Org.). Tradução: Reinaldo Guarany. Rio de Janeiro: Bertrand Brasil, 1998.

A condição humana. 11. ed. Rio de Janeiro: Forense Universitária, 2010.

BALBINOT, E. PEREIRA, B. Particularidades inerentes ao modelo de gestão de um empreendimento de economia solidária: o caso do Projeto Esperança/Cooesperança. In: ENCONTRO NACIONAL DA ASSOCIAÇÃO NACIONAL DE PÓS GRADUAÇÃO E PESQUISA EM ADMINISTRAÇÃO - ENANPAD, 31, 2007. Anais... Rio de Janeiro: Anpad, 2007.

BAUDRILLARD, J. A sociedade de consumo. Lisboa: Edições 70, 1995.

BEHR, R.; PAES DE PAULA, A. Autogestão e lógica de mercado: a experiência da Colônia Cecília e os dilemas da economia solidária. In: ENCONTRO NACIONAL DE ESTUDOS ORGANIZACIONAIS - ENEO, 5., 2008. Anais... Belo Horizonte: Associação Nacional dos Cursos de Pós-Graduação em Administração, 2008.

BÖHM, S. Repositioning organization theory: impossibilities and strategies. New York: Palgrave Macmillan, 2006.

CHANLAT, J. Ciências Sociais e Management: reconciliando o econômico e o social. São Paulo: Atlas, 1999.

CLEGG, S. As organizações modernas. Lisboa: Celta Editora/Oeiras, 1998.

; HARDY, C. Introduction organizations, organization and organizing. In: ; NORD, W. (Eds.). Handbook of organization studies. London: Sage Publications, 1996.

COSTA, P.; CARRION, R. Situando a economia solidária no campo dos estudos organizacionais. In: ENCONTRO NACIONAL DE ESTUDOS ORGANIZACIONAIS - ENEO, 5., 2008. Anais... Belo Horizonte: Associação Nacional dos Cursos de Pós-Graduação em Administração, 2008.

DUARTE, A. Poder e violência no pensamento político de Hannah Arendt. In: ARENDT, H. Sobre a violência. Rio de Janeiro: Relume Dumará, 1994.

. Hannah Arendt e a modernidade: esquecimento e redescoberta da política. Trans/Form/Ação, São Paulo, n. 24, p. 249-272, 2001.

DUMONT, L. Homo Aequalis: gênese e plenitude da ideologia econômica. Bauru, SP: Edusc, 2000.

ESCOBAR, A. Beyond the Third World: imperial globality, global coloniality and anti-globalisation social movements. Third World Quarterly, n. 25, v.1, 2004.

FARIA, J.; LEAL, A.; ATTIE, J. et al. Autogestão e Poder: esquema de análise das relações de poder em organizações com características autogestionárias. In: ENCONTRO NACIONAL DE ESTUDOS ORGANIZACIONAIS - ENEO, 5., 2008. Anais... Belo Horizonte: Associação Nacional dos Cursos de Pós-Graduação em Administração, 2008. 
. ; PONTES, D.; LEAL, A. et al. Categorias de exercício do poder em organizações coletivistas de trabalho. In: ENCONTRO NACIONAL DE ESTUDOS ORGANIZACIONAIS - ENEO, 5., 2008. Anais... Belo Horizonte: Associação Nacional dos Cursos de Pós-Graduação em Administração, 2008.

FRENZEL, F.; BÖHM, S.; SULLIVAN, S. et al. Comparing alternative media in North and South: the cases of IFIW atchnet and Indymedia in Africa. Environment and Planning A, v. 4, n. 5, p. 1173-1189, 2011.

GRAMSCI, A. Cadernos do cárcere. 3. ed. Rio de Janeiro: Civilização Brasileira, 2002. v. 3.

KNOKE, D. Organizing for collective action: the political economics of associations. New York: Aldine de Gruyter, 1990.

LACLAU, E. MOUFFE, C. Hegemony and socialist strategy: towards a radical democratic politics. 2. ed. London, New York: Verso, 2001.

MIZOCZKY, M. Das práticas não-gerenciais de organizar a organização para a práxis da libertação. In: FLORES, R.; MORAES, J. (Orgs.). Organização e práxis libertadora. Porto Alegre: Dacasa Editora, 2010.

; FLORES, R. K; BÖHM, S. A práxis da resistência e a hegemonia da organização. O\&S, Salvador, v. 15, p. 181-194, 2008.

; MORAES, J. Organização e práxis libertadora. Porto Alegre: Dacasa Editora, 2010.

; SILVA, J.; FLORES, R. Autogestão e práticas organizacionais horizontalizadas: amplificando sinais. In: ENCONTRO NACIONAL DE ESTUDOS ORGANIZACIONAIS - ENEO, 5., 2008. Anais... Belo Horizonte: Associação Nacional dos Cursos de Pós-Graduação em Administração, 2008.

; VECCHIO, R. Experimentando pensar: da fábula de Barnard à aventura de outras possibilidades de organizar.

Cadernos EBAPE.BR, Rio de Janeiro, v. 4, n. 1, mar. 2006.

NOGUEIRA, M. A. Em defesa da política. São Paulo: Editora Senac, 2001.

PAES DE PAULA, A. Tragtenberg revisitado: as inexoráveis harmonias administrativas e as burocracias flexíveis. Revista de Administração Pública, v. 36, n. 1, 2002.

. ; RODRIGUES, M. Pedagogia crítica no ensino da administração: desafios e possibilidades. In: ENCONTRO NACIONAL DA ASSOCIAÇÃO NACIONAL DE PÓS GRADUAÇÃO E PESQUISA EM ADMINISTRAÇÃO ANPAD, 30., 2006. Anais... Salvador: Associação Nacional dos Cursos de Pós-Graduação em Administração, 2006.

PARKER, M. Against management: organization in the age of managerialism. Cambridge: Polity, 2002.

RAMOS, A. G. A nova ciência das organizações: uma reconceituação da riqueza das nações. Rio de Janeiro: Fundação Getulio Vargas, 1989.

SANTOS, B. Pela mão de Alice: o social e o político na pós-modernidade. 9. ed. São Paulo: Cortez, 2003.

SCHREVEN, S.; SVERRE, S.; SVENSSON, P. Alternatively. Ephemera theory \& politics in organization, London, v. 8. n. 2. 2008 .

SOLÉ, Andreu. L'entrepise: une invention latine? In: COLÓQUIO SOBRE PODER LOCAL, 9., 2003, Salvador. Anais... [S.l.: s.n.], 2003.

SPICER, A.; BÖHM, S. Moving management: theorizing struggles against the hegemony of management. Organization Studies, n. 28, v. 11, p. 1667-1698, 2007. 
SULLIVAN, S.; SPICER, A.; BÖHM, S. Becoming global (un)civil society: counter-hegemonic struggle and the indymedia network. Globalizations, v. 8, n. 5, p. 703-717, 2011.

TENÓRIO, F. G. Gestão social: uma perspectiva conceitual. Revista de Administração Pública, v. 32, n. 5, 1998.

TRAGTENBERG, M. Burocracia e ideologia. 2. ed. São Paulo: Unesp, 2006.

YOUNG; Z; BÖHM, S. Dis/organising global alternative media: the case of ifiwatchnet.org. Draft paper to be presented at the Social Movements Conference 'Alternative futures and popular protest', 2-4 April 2007, Manchester. Working Paper. 